\title{
Reconhecendo processos simbólicos no ensino de enfermagem por meio de estudos em representações sociais
}

\section{Recognizing symbolic processes in nursing education through studies on social representations}

\author{
${ }^{1}$ Flávia Tocci Boeing Duarte flaviaboeing@ hotmail.com \\ ${ }^{2}$ Patrícia Fernandes lootens Machado
}

\section{RESUMO}

Um dos pilares do curso de enfermagem é o ato de cuidar do ser humano, o que independe dos critérios subjetivos sociais, justamente, porque todos tem o direito e merecem cuidado igualitário. Por isso, este trabalho buscou reconhecer na natureza humana de futuros enfermeiros as representações sociais sobre a doença sífilis, construída histórica e socialmente sobre signos. Com vistas a pensar propostas pedagógicas inspiradas em uma formação reflexiva na perspectiva de formar para a atuação cidadã. Assim, o pecurso metodológico seguiu-se por aplicar um questinário de invetigação de perfil e outro semiprojetivo, sobre o tema sífilis. Os dados foram tratados por meio do softwe IRAMUTEQ, bem como por meio da Análise Textual Discursiva, o que culminou no seguinte resultado: os estudantes demonstram que as ideias consensuais se organizam sob dois eixos, o informacional, indicando o que os sujeitos sabiam a respeito da sífilis e eixo representacional, indicando sentidos valorativos e estigmatizados.

Palavras-chave: Enfermagem. Ciências da Saúde. Educação Científica.

\begin{abstract}
One of the pillars of the nursing course is the act of caring for the human being, which does not depend on subjective social criteria, precisely because everyone has the right and deserves equal care. Therefore, this work sought to recognize in the human nature of future nurses the social representations of the syphilis disease, historically and socially constructed on signs. With a view to thinking about pedagogical proposals inspired by a reflective training in the perspective of training for citizen action. Thus, the methodological path was followed by applying a profile investigation questionnaire and a semi-projective questionnaire on the topic of syphilis. Data were processed using the IRAMUTEQ softwe, as well as using Discursive Textual Analysis, which culminated in the following result: students demonstrate that consensual ideas are organized under two axes, the informational, indicating what the subjects knew about of syphilis and representational axis, indicating evaluative and stigmatized meanings.
\end{abstract}

Keywords: Nursing. Health. Science Education.

1 Universidade de Brasília. ORCID: https://orcid.org/ 0000-0001-8513-3096

2 Universidade de Brasília. ORCID: http://orcid.org/0000-0003-0219-1472 


\section{INTRODUÇÃO}

A educação científica apresenta entre outros propósitos, a formação para a cidadania. A educação com vistas à cidadania que nos referimos, é aquela compreendida por Freire (2001) como a capacidade em que o ser humano tem em tomar propriedade de sua realidade e transformá-la, possibilitando novos sentidos. Na educação científica, essa é uma ideia que estabelece o objetivo de colaborar com a construção de uma sociedade atuante, diante de questões que envolvem a ciência e a tecnologia. Nesse sentido, pesquisadores da área tem sinalizado para a importância do desenvolvimento da cultura de participação social, no âmbito da formação da educação científica. De modo que, possamos pensar uma formação que possibilite aos estudantes a apropriação do conhecimento científico e, ao mesmo tempo, os aperfeiçoe para atuar em diferentes espaços sociais, como por exemplo, em processos de democratização de decisões que compreendem temas sociais científicos-tecnológicos (ROSA e STRIEDER, 2021; SANTOS e AULER, 2011).

Deste modo, o ensino se volta para a construção de uma sociedade consciente e preocupada com os propósitos da ciência e da tecnologia, bem como, com as situações de desigualdades socais que delas emergem. Esses princípios são amplamente defendidos pela Educação com ênfase nas relações Ciência-Tecnologia-Sociedade (CTS). A qual prevê uma educação pautada na formação de valores e no desenvolvimento do ser humano consciente de seu papel social, principalmente no que remete a tomar decisões em seu contexto e no âmbito da sociedade científico-tecnológica (SANTOS E AULER, 2011).

A Educação CTS tem sido reconhecida como estratégica para formação profissional ética e humanizada, como observa Santos e Auler (2011). Sendo, essa uma vertente educacional cada vez mais desejada em áreas como o ensino de ciências da saúde, que se modifica pela inserção de novas tecnologias e conhecimentos científicos-tecnológicos, principalmente em razão de circunstâncias epidemiológicas.

Dentre os cenários epidemiológicos atuais brasileiros, encontra-se a situação da doença sífilis. Vivemos hoje no Brasil, uma situação epidemiológica preocupante, já que dados do último relatório epidemiológico do Ministério da Saúde indicam um aumento significativo de novos casos nos últimos anos de pessoas infectadas, segundo o boletim epidemiológo apresentado pelo Ministério da Saúde, em 2017. No Distrito Federal, também tem sido observado um crescimento do coeficiente de detecção de sífilis, como revela os dados do informativo epidemiológico da sífilis divulgado pela Subsecretaria de Vigilância à Saúde e pela Secretaria de Saúde do Distrito Federal, no ano de 2021. O qual indicou a notificação de 9.025 casos novos da doença na modalidade adiquirida, sem considerar as gestantes, no periodo de entre 2016 a 2020.

Muito embora a sífilis seja uma doença medieval instalada na humanidade no Século XIII este informativo revela que a doença permace latente na sociedade. No passado, a sífilis era interpretada como um castigo que fazia jus a libertinagem e a uma vida sem regras. A doença teria um papel essencial na limitação sexual, principalmente dos jovens, colaborando para a conservação de sua saúde. Foi no Século XIX, que a enfermidade passou a ser reconhecida no meio acadêmico como uma doença perigosa e associada às práticas sexuais, que na época, consideradas impuras, já que retratava o despudor presente na sociedade. A busca do tratamento adequado era comprometida pelo sentimento de vergonha da doença, impedindo atitudes racionais, inclusive pela vigilância (CARRARA, 1996).

Entretanto, essas visões retóricas sobre a sífilis parecem ter transcendido o passado ao presente, é o que indicou um estudo realizado por Mauch (2011). Nele, a pesquisadora observou o significado da sífilis no universo masculino do Distrito Federal e constatou que na percepção dos participantes da pesquisa, a doença está associada ao homossexualismo e a prostituição, indicando o que autora descreve como uma representação social arcaica da doença venérea.

É importante destacar, que profissionais de saúde, frequentemente, irão se deparar com pacientes acometidos não apenas pela sífilis, mas também por diversas outras doenças impregnadas de valores éticos e morais, 
construído e transmitido ao longo de gerações, sedimentados como um saber social. Justamente por isso, que estudos alicerçados sob a luz da Teoria das Representações podem ser um mecanismo interessante de produção de conhecimento para pesquisas em educação. Jodelet (1989) aclara, que as Representações são reflexos dos saberes sociais, atribuídas aos valores simbólicos, interesses políticos e dotadas de cientificismo. A autora, adjudicou às representações a faculdade de justificar os comportamentos discriminatórios, levando assim, exclusão e humilhação de outros. Deste modo, as representações sociais revelam manifestações do senso comum, credo e mitos sobre dado objeto de representação social, como a doença sífilis.

Logo, esta proposta contribuirá para vislumbrar quais manifestações de senso comum, com suas atribuições de valores simbólicos, implicam na formação dos enfermeiros. A partir da reflexão sobre o exposto surgiram problemáticas norteadoras deste estudo: 1. Quais valores simbólicos estruturam as representações sociais (RS) de estudantes de enfermagem de uma faculdade particular do Distrito Federal sobre a temática sífilis? 2. De que modo essas Representações podem influenciar a atuação profissional desses alunos? Portanto, objetiva neste estudo compreender quais são, e, como são estruturadas as representações sociais de estudantes de enfermagem, acerca da sífilis, afim de, subsidiar informações para uma proposta de formação profissional na perspectiva da educação científica.

Para tanto, as seções seguintes foram sistematizadas na seguinte ordem: caracterização da sífilis, a Teoria das Representações Sociais, metodologia e resultados discutidos.

\subsection{Sífilis, do que se trata?}

A sífilis é determinada como uma IST, ou seja, uma infeção sexualmente transmissível, que tem como agente etiológico o microrganismo Treponema pallidum, uma bactéria identificada em 1905. E, mesmo com a descoberta do agente causador da doença, esta permaneceu incurável por um período de 38 anos. Posteriormente, a descoberta da penicilina como um bactericida, em 1943, a cura passou a ser possível (DISTRITO FEDERAL, 2021).

A sífilis é descrita como uma doença de infecção sistêmica, crônica, curável e, peculiar a espécie humana. Ela pode ser, por meio de relações sexuais ou verticalmente para o feto, no período gestacional de uma mulher com sífilis não tratada ou tratada inadequadamente. É, importante ressaltar, que esta é uma enfermidade que apresenta períodos de atividade e de latência, o que leva a um quadro assintomático momentâneo contribuindo para a evolução de quadros mais graves da doença e a sua transmissão inconsciente (DISTRITO FEDERAL, 2021).

\subsection{As premissas da Teoria das Representações Sociais}

A compreensão que hoje temos sobre as representações sociais (RS) foi apresentada por Moscovici em 1961, por meio de um estudo sobre temas voltado para a área da psicanálise e da psicologia social. O francês Serge Moscovici desenvolveu a Teoria das Representações Sociais durante os anos de 1950 a 1961, ao investigar como a população francesa entendia a psicanálise por meio das informações da impressa, o que culminou em sua tese de doutorado intitulada "Psychanalyse, son image et son publique". Seu trabalho estendeu-se por temas quanto ao processo social de produção e a apropriação de conhecimento científico, por parte da sociedade (ALVES-MAZOTTI, 2008).

Por definição, as representações sociais são semelhantes ao conhecimento consensual, ou seja, é um saber compartilhado dentro de grupos, que tende a determinar o modo como as pessoas agem, pensam, e tomam decisões diante de um objeto de representação (MOSCOVICI, 2015), como por exemplo a doença sífilis. De acordo com Lopes (1999), este é um tipo de conhecimento que se caracteriza por ser instrumento de ação de valor social ao produzir efeitos práticos, gerando assim, um pensamento pragmático, objetivo e direto. Ele reflete a nossa cotidianeidade, na qual temos um modo de vida instintivo, familiar e espontâneo. 
O senso comum é autor de um saber consensual que reflete nas representações sociais, quando essas são infligidas por valores simbólicos, interesses políticos e, por vezes, construções históricas pautadas em cientificismo. Isso estabelece às representações a propriedade de sistemas referências, acessados quando há necessidade de um indivíduo justificar suas ações ou decisões, o que potencialmente levaria a práticas sociais de domínio sobre o outro. O outro, inconsciente e conformado com a justificativa do saber consensual, renuncia sua capacidade de agir, de decidir e de ser. Dominado por uma força ideológica, acomoda-se, não se opõem às velhas concepções, torna-se anônimo, passivo a história da sua vida, assim pode-se refletir a apartir dos pressupostos freireanos.

Logo, o estudo dessas representações poderia nos ensinar sobre a maneira como as pessoas pensam e realizam suas ações ou como elaboram um conhecimento produzido e sustentado por grupos sociais específicos (MOSCOVICI, 2015) e de modo esse saber consensual marca as ações do grupo. Igualmente, poderia nos esclarecer como são construídas e compartilhadas as crenças e mitos sobre algo, a exemplo, as concepções da doença sífilis.

O pensamento é considerado como uma atmosfera social e cultural do ambiente em que vivemos, pois estamos cercados de ideias, valores e simbolizações que nos alcançam, por vezes, de forma inconsciente. Isto é o que caracteriza as representações sociais (RS), que por sua vez, definem-se como sistemas de valores que surgem da visão de como compreendemos um objeto, ou quando adquirimos uma capacidade de definição e função de identidade dentro de um grupo ou de modo particular (JODELET, 1989). A dinâmica das relações e das práticas sociais de uma pessoa em um meio social estabelece a formação de sistemas de referência, que é usado para identificar, resolver e explicar situações problemáticas, ou ainda, fenômenos que surgem no nosso dia-a-dia. Sendo assim, as representações são compreendidas como um fenômeno social, o que imediatamente, nos remete a processos educacionais.

Alves-Mazotti (2008) explica que parece promissor estudar as representações sociais e aplicá-las com o propósito de investigar como são estruturados e construídos os sistemas de referência que empregamos para classificar pessoas e grupos. E, ainda, pode favorecer o entendimento de questões cotidianas, pois, possibilitaria o estudo das interações entre linguagem, ideóloga e imaginação, além de orientar condutas e práticas sociais. Na perspectiva de se trabalhar com a temática sífilis, estudos dessa magnitude são valorados.

No âmbito da Educação Científica investigar as representações sociais de determinadas temáticas, pode ser um caminho para o entendimento de como os fatores sociais atuam sobre os processos formativos impactando seus resultados.

Contudo, tendo caracterizado o campo de desenvolvimento deste trabalho, o qual se insere so o aporte teórico da Teoria das Representações Socias os propósitos, delineou-se o percurso metodológico apartir dos seguintes critérios: carcaterizar o perfil dos participantes da pesquisa; identificar as representações sociais acerca da sífilis do grupo em questão; comprender como estão estruturadas tais representações e propor uma reflexão/ ção de possíveis caminhos para a superação de estigmas sociais sobre a doença sífilis na formação de estudantes de enfermagem. Percusos esses, que serão descritos a seguir.

\subsection{Delineamento Metodológico}

Em uma pesquisa social, qualitativa, na qual se busca compreender o mundo cotidiano de um grupo, a melhor forma para coletar dados é a entrevista, como aponta Gaskell (2015). Logo, foram aplicados dois questionários (Quadro 1) um de caracterização de perfil do grupo e outro de investigação das representações sociais sobre o obejto de representação, a doença sífilis. Conforme Almeida (2005) o questionário semiprojetivo é adequado para uma investigação sobre representações sociais por permitirem que os sujeitos formulem respostas a respeito de dado objeto. 


\section{Quadro 1 - Questionário de Investigações das Representações Sociais, com adaptações a partir do trabalho de Mauch (2011).}

\begin{tabular}{|l|l|}
\hline Questionário de perfil & Questionário semi-projetivo \\
\hline & $\begin{array}{l}\text { Continue a frase iniciada abaixo, colocando as suas ideias de } \\
\text { modo complementar. }\end{array}$ \\
Sexo: Masculino/Feminino & 1 A sífilis é causada por... \\
Formação Inicial (Área): & 2. A sífilis é transmitida por... \\
Tem alguma religião qual? Semestre ao qual está & 3. Eu posso evitar a sífilis quando... \\
cursando? & $\begin{array}{l}\text { 4. Escreva três palavras que lhe vem à cabeça quando você pensa } \\
\text { Trabalha, em que área? }\end{array}$ \\
em Séfilis: & 5. Quando imagino a sífilis eu vejo... \\
& 6. O paciente que contraí a sífilis pode tratar a doença com.... \\
\hline
\end{tabular}

No que se refere a análise e interpretação dos dados, apoianomos-nos na Análise Textual Discursiva (ATD), bem como, na análise lexicográfica, por meio do recurso do software IRAMUTEQ (Interface de R pour les Analyses Multidimensionnelles de Textes et de Questionnair). A Análise Textual Discursiva (ATD) suplanta a visão de ser apenas um conjunto de técnicas de análise de um corpus. Como argumentam os autores Moraes e Galiazzi (2006, p. 118): "o envolvimento na análise textual discursiva propiciaram duas reconstruções concomitantes: o entendimento da ciência e de seus caminhos de produção; a sua compreensão do objeto da pesquisa". Os autores justificam que a ATD cria espaços de reconstrução sempre a partir das vivências de quem passou pelo processo, envolvendo-se nisso elementos diversificados, especialmente a compreensão dos modos de produção da ciência e reconstruções de significados dos fenômenos investigados. Deste modo, a ATD é exponencialmente um recurso de análise de dados interessante para estudos em Representações Sociais (RS).

Já a análise lexicográfica permite construir um olhar estrutural de uma RS. Investigações de como se estruturam uma representação social é sustentada, sob a Teoria do Núcleo Central proposta por Abric (2001), a qual se debruça sobre como os conteúdos das representações são organizados, considerando questões como estabilidade e mudança e a sua relação com a prática social (FELIX et al., 2016).

Abric (2001) propõe uma hipótese a respeito da organização estrutural interna das representações sociais, intitulada a Teoria do Núcleo Central. Essa teoria considera que uma RS está organizada em torno de um Núcleo Central, esse núcleo seria o elemento fundamental da Representação, logo também incide no significado e na organização da Representação. O Núcleo central ou estruturante de uma RS contempla as seguintes funções essenciais: a geradora refere-se à criação do elemento central e transforma o significado de outros elementos periféricos que estão interligados ao núcleo central, assim assume-se um valor ou significado. E a organizadora determina que seja o núcleo central quem destrói a natureza dos laços que conectam os elementos constitutivos da RS, portanto a partir disso, tem-se a reestruturação e modificação das representações.

Os elementos periféricos constituem esta interface entre o núcleo central e a situação concreta, Abric (2001) explica que nesse caso as funções da RS seriam: a função concreção: condicionada ao contexto, uso de termos de fáceis para o entendimento de assuntos cotidianos; regulação elementos periféricos são flexíveis para adaptar as Representações ao contexto; e função de defesa, o núcleo central de uma representação é resistente à mudança, uma vez que sua transformação causa uma desordem completo. Em síntese, um sistema central está intensamente conexo com as construções históricas, com o sociológico e ideológico. E, diretamente coligado aos valores e normas, que determinam os alicerces que constituem uma representação social. 


\section{RESULTADOS E DISCUSSÕES}

O trabalho de campo foi realizado em uma turma do $2^{0}$ semestre do curso de enfermagem, em uma instituição privada do Distrito Federal, no ano de 2019. A primeira coleta de dados ocorreu por meio da aplicação do questionário de investigação do perfil do aluno. Neste, buscou-se conhecer e caracterizar as possíveis variáveis sociais que poderíamos relacionar as experiências dos participantes e associar à construção de suas representações. De acordo com as análises realizadas, $25 \%$ dos participantes já atuam na área de saúde, demostraram trabalhar em hospitais, como técnicos, consultórios odontológicos e como cuidadores de idosos. 100\% dos participantes eram do sexo feminino. Em relação a terem a formação técnica na área da saúde, 33,33 \% responderam que cursaram o curso técnico em enfermagem.

Gráfico 1 - Análise de perfil do grupo, considerando as variáveis, sexo, atuação profissional, formação inicial e religião.

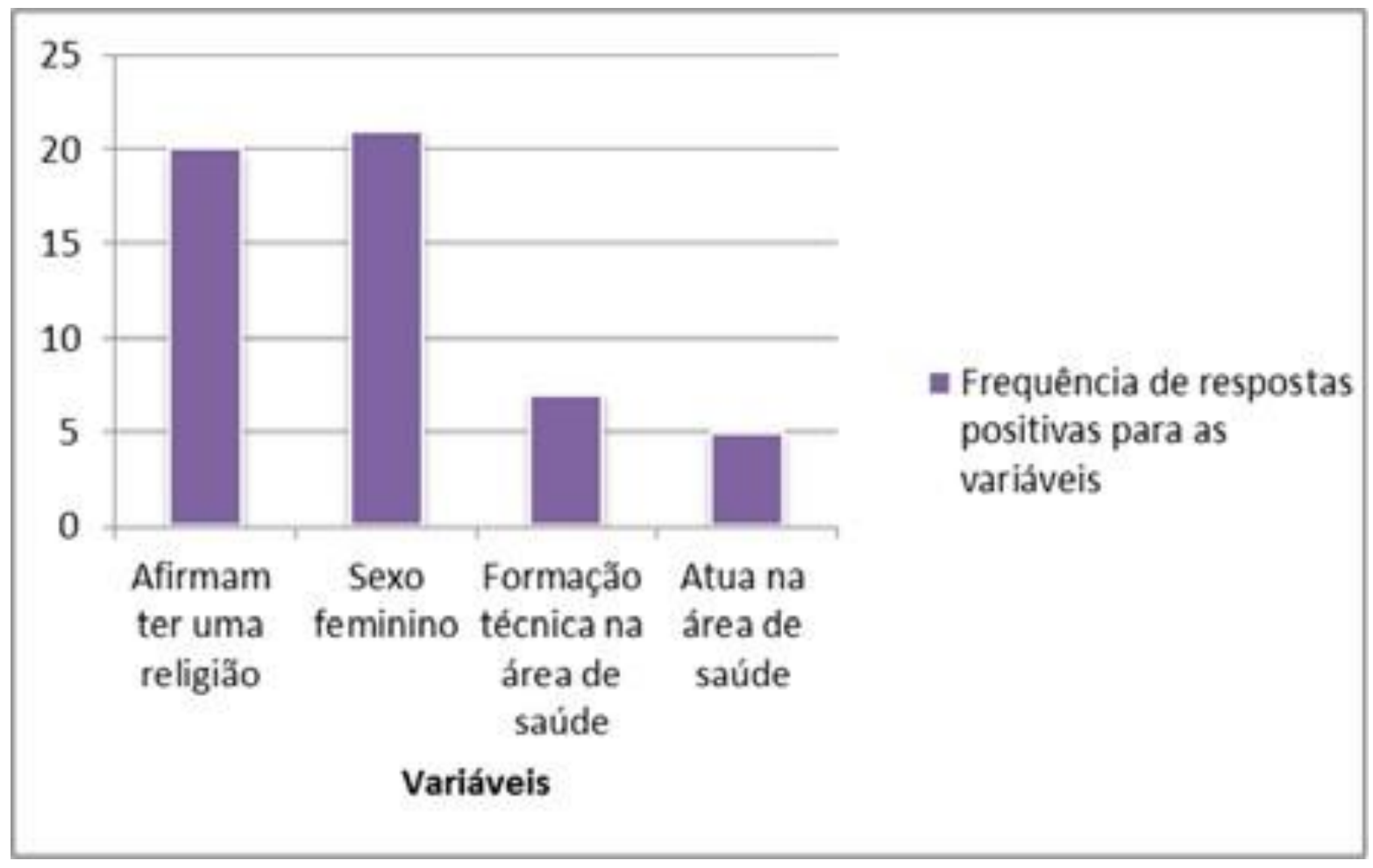

Fonte: ?

\subsection{Investigando as Representações Sociais sobre a temática sífilis}

Os desdobramentos que decorreram da construção metodológica deste estudo tiveram dois direcionamentos, como já supracitado, a Análise Textual do Discurso (ATD) e a Análise Lexicográfica do corpus de análise. A análise Lexicográfica possibilitou compreender a estrutura e a constituição de elementos representativos mais significativos das representações sociais. Como evidencia Saviat (2017) vale destacar, que análise lexical das representaçoes sociais tem algumas limitações, pois, ao demonstrar uma frequência de classe de palavras, observamos a existência de certo campo contextual, indicando uma representação local e imediata, não nos revela os significados que transcendem as palavras escritas. Por isso a relevância de associar duas metodologias de análise de dados, neste caso, Lexical e a Textual Discursiva, que serão apresentadas a seguir. 


\section{2 Análise Lexicográfica}

A verificação da Análise lexical gerou uma nuvem de palavras (Figura 1), constituída de elementos representativos mais significativos sobre a temática. $\mathrm{O}$ tamanho dos termos está relacionado à quantidade de vezes em que estes aparecem nos corpus na analisado, logo, quanto maior o termo, maior é sua frequência.

Figura 1 - Diagrama nuvem de palavras a partir do tema indutor sífilis gerado pelo software IRAMUTEQ

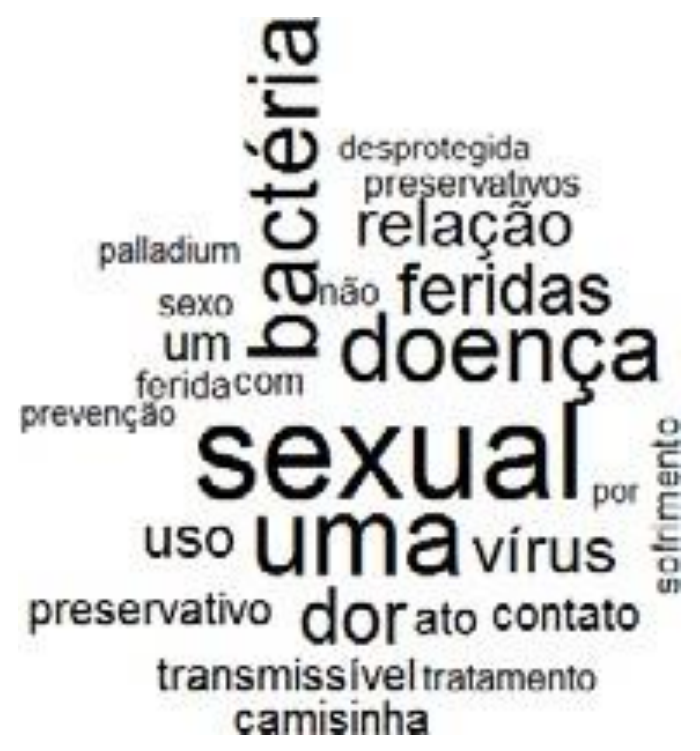

Fonte: ?

Observa-se que a palavra 'sexual' aparece no discurso dos alunos trinta e três vezes, seguida de 'preservativo' com ocorrência de quinze vezes, 'bactéria', surge treze vezes e o termo 'relação', que surge dez vezes. Além dessas, há frequência relativa das palavras 'dor', 'vírus' e 'transmitida'. As demais indicadas aparecem no texto dos interlocutores da pesquisa entre 6 vezes a uma vez (Figura 2).

Nascimento e Menandro (2006), explicam que há uma relação entre o contexto linguístico e uma representação coletiva. A presença de um enunciado mínimo em um discurso percebe-se uma ideia de um indivíduo psíquico a respeito de um objeto, e ao mesmo tempo de um sujeito. Essa relação dialética permite a formação da representação de um objeto. Os autores esclarecem que: “... a regularidade de representações entre indivíduos pode promover a existência de um determinado contexto típico de um grupo, uma representação coletiva, um mundo" (p.32). De tal modo, ao investigar vocabulários específicos pode-se entender como está alicerçado compreensão de determinado objeto, por grupos ou pessoas, pois diferentes palavras representam formas distintas de discurso. 
Figura 2 - Gráfico de frequência de termos na forma reduzida das classes de palavras, verbo, substantivos e adjetivos.

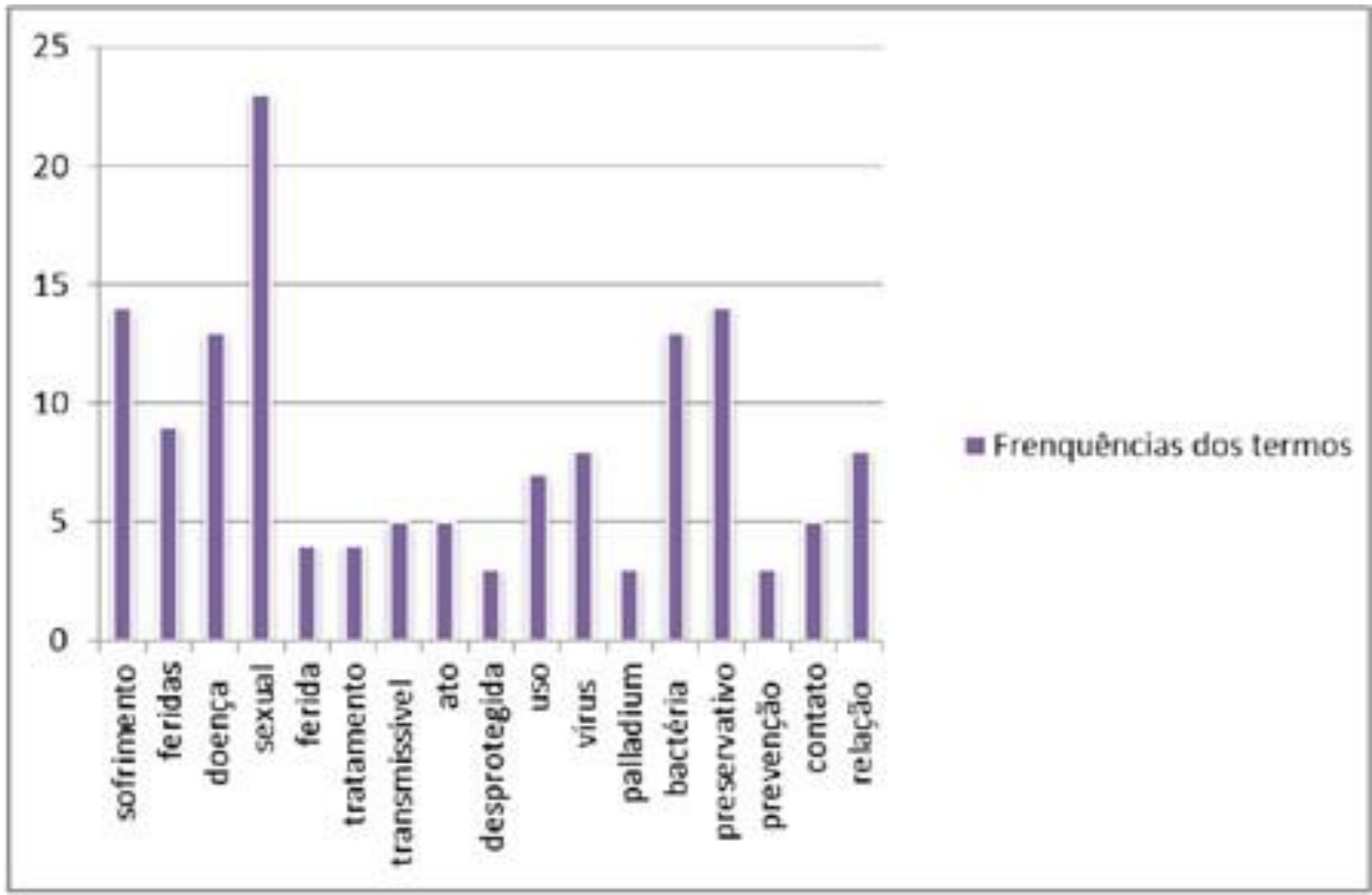

Fonte: ?

Infere-se dos dados que a maior ocorrência do termo sexual associado a doença sífilis, poderia indicar que os participantes da pesquisa tendem a atribuir à doença, o modo de transmissão por relação sexual. De fato esta é uma forma importante de transmissão que determina inclusive se uma doença é uma IST. Entretanto não podemos esquecer que não é a única maneira de contrair a doença, pois a transmissão também pode acorrer de forma verticalmente para o feto, por gestantes que contraíram a sífilis e não buscaram tratamento, ou que trataram de maneira inadequada.

Mauch (2011), realizou um estudo que investigou as representações sociais de um grupo de homens do Distrito Federal sobre a sífilis. Em seus resultados, a autora identificou elementos semelhantes aos nossos achados, levando a inferência de que há realmente uma tendência das pessoas dar sentido sexual para a doença sífilis, neste caso, atribuiu-se a ela uma possível representação de estereotipação. Sobre o termo preservativo surge como segunda palavra que mais aparece nos textos analisados, isso pode estar associada à aceitação desse produto pela sociedade. Mauch (2011) explica que investigações acerca do uso de preservativos como objeto de representação social, revelaram que 45,6\% de pessoas entrevistadas demonstraram aceitar claramente o uso de preservativos.

O termo bactéria aparece de modo significativo como agente causador da doença, e o termo vírus, erroneamente. Demonstrando conflito conceitual na compreensão do conhecimento científico sobre a biologia desses diferentes microrganismos. Ressalta-se que os participantes da pesquisa são alunos da disciplina de microbiologia, e, que a pesquisa foi realizada ao final do semestre letivo. Diferenciar os microrganismos como vírus e bactérias, é uma competência prevista para a disciplina. Deste modo, os discentes já tinham o conhecimento sobre esses patógenos, tendo recebido informação suficiente para tal. É possível que este seja um indicativo informacional, no qual, há o desconhecimento de qual seria o agente causador da sífilis. Isso implica também na 
compreensão do tratamento e na busca do direito a ele. Isso é preocupante, considerando a formação de um futuro enfermeiro. Se avaliarmos a frequência de ocorrência do termo tratamento, este ocorre apenas quatro vezes.

Outros termos representacionais surgem no discurso dos sujeitos da pesquisa, como medo, dor, doença, beijo, desespero, vergonha e nojo e estão relacionadas aos valores e sentidos simbólicos. Denise Jodelet (1989) fala em sua obra sobre a influência das ideias de senso comum no período do surgimento da AIDS (Síndrome da Imunodeficiência Adquirida). É possível que haja uma forte representação social do grupo atribuindo o contágio por relação sexual, logo, estereotipando a causa e delimitando a o modo de transmissão. Compreende-se que esta seria uma afirmação generalizada.

\subsection{Análise Textual Discursiva}

Complementar a análise lexicográfica propõe-se a Análise Textual Discursiva (ATD). A partir desta análise observou-se a presença de eixos estruturantes nas respostas dos participantes da pesquisa, o informacional e representacional (Figura 3). Mauch (2011) explica que o primeiro determina o que os alunos sabem a respeito da sífilis e quais informações se apropriaram e propagaram. Outro designa ideia de imagem do objeto, considera valores, atitudes, opiniões e sentidos subjetivos construídos a partir de um coletivo, respectivamente.

\section{Figura 3 - Diagrama das categorias resultantes da Análise Textual Discursiva, emergindo duas categorizações: $o$ eixo informacional e representacional.}

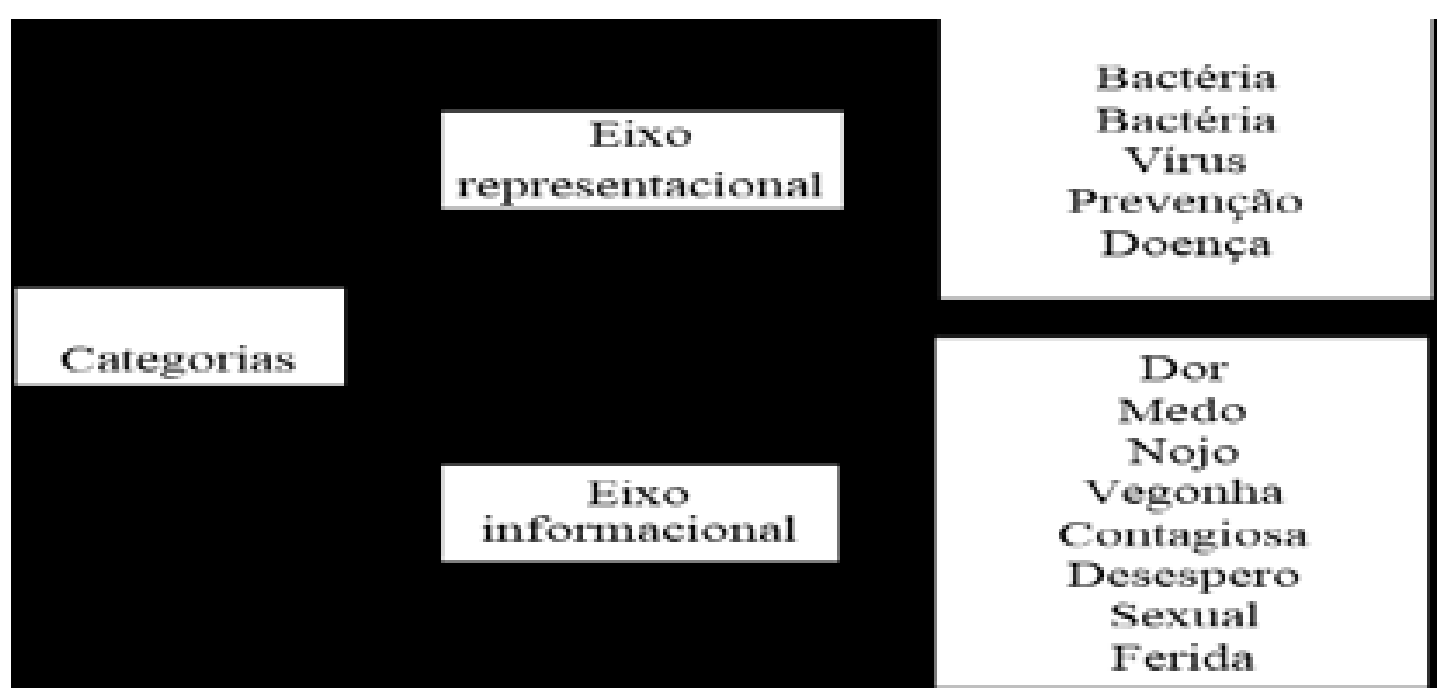

Fonte: ?

As categorias do eixo informacional apontaram para a necessidade de ativar elementos relacionados à prevenção da sífilis na representação social, bem como ficou evidenciado a não compreensão das alunas sobre os protocolos de tratamento para essa enfermidade. Já os termos, classificados no eixo representacional como, medo, nojo e vergonha são sentidos valorativos de cunho moral e ético, assim podem levar ao preconceito e a supressão de um atendimento alinhado aos portadores de sífilis.

\section{CONSIDERAÇÕES FINAIS}

O pensamento da análise e da compreensão do papel da educação científica na formação para a cidadania, que nos move a propor este diálogo entre a Teoria das Representações Sociais e a Educação Científica, sob o ponto de vista humanístico para a formação de futuros enfermeiros. Buscou-se com este trabalho, contribuir para a da formação da cidadania em Freire. No ímpeto de pensar novas acões formativas para a educação superior 
em cursos da área de ciências da saúde. Ressalta-se que, a adoção do estudo das Representações Sociais neste trabalho, partiu do interesse em compreender o que os alunos pensam sobre a sífilis, além de caracterizar o perfil do grupo, e, a partir disso, pensar em aspectos sociocientíficos que fossem expressivos para as suas formações.

Na perspectiva de revelar a realidade e despertar para a participação social, procuramos alinhar o objetivo da Educação Científica e a TRS como possibilidade de restruturação de ideias arcaicas e estigmatizadoras. A reflexão que este trabalho nos convida é a de que, se o grupo investigado pode desenvolver a capacidade de reconhecer ideias generalistas e consolidadas no meio social sobre a doença estigmatizadas levando a refletir sobre sua prática profissional. Possibilitando a (re)significação de ideias, por meio de ações educativas propositais.

\section{REFERÊNCIAS}

ABRIC, J. C. A abordagem estrutural das representações sociais. In: MOREIRA, A. S. P.; OLIVEIRA, D. C. (Org.). Estudos interdisciplinares de representação social. 2. ed. Goiânia: AB, 2001. p. 27-37.

ALMEIDA, A. M. O. A Pesquisa em representações sociais: proposições metodológicas. In: SANTOS, M. F. S.; ALMEIDA, L. M. (Org.). Diálogos com a teoria da representação social. Universidade Federal de Pernambuco - UFPE, 2005. p.117-160.

ALVES-MAZZOTTI, A. J. Aspectos teóricos e aplicações à educação. Revista Múltiplas Leituras, v.1, n. 1, 2008. p. 18-43.

BACHELARD, G. Le nouvel ésprit scientifique. Paris: quadridge/ Presses Universitaires de France, (1991). Tradução por Juvenal Hahne Junior. O novo espirito científico. Rio de janeiro: tempo Brasileiro. 1996, p. 47-148.

CARRARA, S. Tributo a Vênus: a luta contra a sífilis no Brasil, da passagem do século aos anos 40, Rio de Janeiro: Editora FIOCRUZ, 1996, p. 339.

DISTRITO FEDERAL. Gerência de Vigilância das Infecções Sexualmente Transmissíveis (GEVIST), da Diretoria de Vigilância Epidemiológica (DIVEP), da Subsecretaria de Vigilância à Saúde (SVS), da Secretaria de Estado de Saúde do Distrito Federal (SES-DF). Informativo Epidemiológico: perfil epidemiológico da sífilis no Distrito Federal, 2016 a 2020.

FELIX, L. B.; ANDRADE, D. A.; RIBEIRO, F. S.; CORREIA, C. C. G.; SANTOS, M. F. S. O conceito de Sistemas de Representações Sociais na produção nacional e internacional: uma pesquisa bibliográfica. Psicologia e Saber Social, 5(2), 2016, p. 198-217.

Freire, P. Política e Educação, $5^{\text {a }}$ ed. Editora: Cortez, 2001.

JODELET, D. Representations sociales: un domaine en expansion. Em, D.Jodelet (Org.) Les Representations Sociales. Paris: Presses Universitaires de France, 1989.

MAUCH, S. D. N. O significado da Sífilis no Universo Masculino: um estudo em Reapresentações Sociais. Dissertação de Mestrado - Departamento de psicologia. Universidade de Brasília, 2011, p. 174.

MINISTÉRIO DA SAÚDE. Secretaria de Saúde. Diretoria de Vigilância Epidemiológica. Coordenação Nacional de Doenças Sexualmente Transmissíveis e AIDS. Boletim Epidemiológico de Sífilis. Ano 06, n.1. Brasil, 2017.

MOSCOVICI, S. Representações sociais: investigações em psicologia social. 2. ed. Petrópolis: Vozes, 2015. 
NASCIMENTO, A. R. A.; MENANDRO, P. R. M. (2006) Análise lexical e análise de conteúdo: Uma proposta de utilização conjugada. Estudos e Pesquisas em Psicologia, 2006, p.72-88.

ROSA, S. E.; STRIEDER, R. B. Perspectivas para a constituição de uma cultura de participação social ampliada em temas sociais de ciência-tecnologia. Revista Brasileira de Pesquisa em Educação em Ciências - RBPEC, 2021.

SANTOS, W. L.; AULER, D. (Org.) CTS e educação científica: desafios, tendências e resultados de pesquisa. Brasília: editora Universidade de Brasília, 2011, p. 460. 